\title{
Evaluation Method of Granite Multiscale Mechanical Properties Based on Nanoindentation Technology
}

\author{
Man Lei $\mathbb{D},^{1,2}$ Fa-ning Dang $\mathbb{D}^{1,2}$ Haibin Xue $\mathbb{D}^{1,2,3}$ and Mingming He $\mathbb{C}^{1}$ \\ ${ }^{1}$ Institute of Rock and Soil Mechanics, Xi'an University of Technology, Xi'an 710048, China \\ ${ }^{2}$ State Key Laboratory of Ecohydraulics in Northwest Arid Region, Xi'an University of Technology, Xi'an 710048, China \\ ${ }^{3}$ National Engineering Laboratory for Surface Transportation Weather Impacts Prevention, Kunming 650200, China
}

Correspondence should be addressed to Haibin Xue; xhbyts2013@163.com

Received 15 April 2021; Revised 2 August 2021; Accepted 12 August 2021; Published 15 September 2021

Academic Editor: Constantinos Loupasakis

Copyright ( ) 2021 Man Lei et al. This is an open access article distributed under the Creative Commons Attribution License, which permits unrestricted use, distribution, and reproduction in any medium, provided the original work is properly cited.

In order to study the mechanical properties of granite at the micro- and nanoscale, the load-displacement curve, residual indentation information, and component information of the quartz, feldspar, and mica in granite were obtained using a nanoindentation test, a scanning electron microscope (SEM), and X-ray diffraction (XRD). The elastic modulus and the hardness of each component of the granite were obtained through statistical analysis. Treating rock as a composite material, the relation between the macro- and microscopic mechanical properties of rock was established through the theory of micromechanical homogenization. The transition from micromechanical parameters to macromechanical parameters was realized. The equivalent elastic modulus and Poisson's ratio of the granite were obtained by the Self-consistent method, the Dilute method, and the Mori-Tanaka method. Compared with the elastic modulus and the Poisson ratio of granites measured by a uniaxial compression test and the available data, the applicability of the three methods were analyzed. The results show that the elastic modulus and hardness of the quartz in the granite is the largest, the feldspar is the second, the mica is the smallest. The main mineral contents in granite were analyzed using the semiquantitative method by XRD and the rock slice identification test. The elastic modulus and the Poisson ratio of granite calculated by three linear homogenization methods are consistent with those of the uniaxial compression test. After comparing the calculation results of the three methods, it is found that the MoriTanaka method is more suitable for studying the mechanical properties of rock materials. This method has an important theoretical significance and practical value for studying the quantitative relationship between macro- and micromechanical indexes of brittle materials. The research results provide a new method and an important reference for studying the macro-, micro-, and nanomechanical properties of rock.

\section{Introduction}

Granite is widely used in the construction of hydropower stations, underground nuclear waste storage, and tunnel engineering because of its good mechanical properties, such as dense structure, high strength, and resistance to weathering. Many scholars have done a lot of research on the macro-, micro-, and nanomechanical properties of rocks [1-4]. However, there are relatively few studies on the transition from the micro- and nanoscale mechanical properties to the macromechanical properties of rocks. The microstructure of granite and its mechanical properties are studied by the nanoindentation technology in this paper. Here, an attempt to study the macromechanical properties of the granite from the micro- and the nanoscale of minerals is made.

Nanoindentation is a very effective method to study the micro- and nanomechanical properties of materials $[1,2$, 5-7]. In recent years, researchers have begun to use this method to study the mechanical properties of rocks. Viktorov et al. [8] studied the strength and deformation properties of minerals in rocks by using nanoindentation. Zhu et al. [9] reported a study to assess nanoindentation mapping of mechanical properties of natural rocks. Zhang et al. [10] studied the micromechanical properties of granite by the nanoindentation test, which provided a reference for determining the macromechanical properties of rock from a 
microscopic perspective. Liu et al. [11] obtained the quantitative relationship between fracture toughness and elastic modulus of shale based on the energy analysis method, which provided a good perspective for understanding the nanomechanical behavior of rocks. All in all, regarding rocks as homogeneous materials, many scholars studied the micro- and nanomechanical properties of rocks by the nanoindentation technique. However, there are relatively few studies that consider the heterogeneous characteristic of rock and reveal the macromechanical properties of granite from the micromechanical properties of minerals.

Due to the difficulty of taking standard core samples in deeply buried engineering and the destruction of the original structure by sampling in important parts of existing engineering, a large number of macromechanical tests cannot be carried out. In this case, the macromechanical parameters of rocks can be calculated by the micro- and nanomechanical parameters, and nanoindentation technology is an effective way to measure the micro- and nanomechanical parameters of materials. In other words, the micromechanical properties of rocks can be obtained by nanoindentation tests and related algorithm; however, the macromechanical behavior of rocks are usually more focused in practical engineering. Therefore, it is a key scientific problem to establish the relationship between the macro- and micromechanical indexes of rocks at different scales. Bobko et al. [12], Chen et al. [13], and Abou et al. [14] proposed some homogenization methods and micromechanical models to estimate the macromechanical properties of materials. The advantages and disadvantages of each method were analyzed.

Granite is regarded in this paper as a material mainly composed of quartz, feldspar, and mica. The linear homogenization theory of composite materials is introduced into the cross-scale study of the macro-, micro-, and nanomechanical properties of granite. The quantitative relationship between the micromechanical indexes and the macromechanical indexes is established by using the Self-consistent method, the Dilute method, and the Mori-Tanaka method. Comparing the results calculated by these three methods with the mechanical parameters measured by the experiment and combining with the advantages and disadvantages of the three methods, an appropriate method is recommended to analyze the relationship between macro- and micromechanical properties of granite. The research results will be helpful in studying the micro- and nanomechanical properties of rocks and in realizing the transition from micro- and nanomechanical parameters to macromechanical parameters.

\section{Test Techniques and Procedures}

2.1. Testing Device. Nanoindentation is a kind of testing technology where an indenter is pressed vertically into the sample surface and the indentation depth and the corresponding load are recorded. The micro- and nanomechanical parameters of the material are calculated according to the load-displacement curve of the material. The nanoindentation tests are carried out on the Agilent Nanoindenter G200, which is shown in Figure 1. Load control mode is adopted in the test. The maximum load of the test is $500 \mathrm{mN}$, and the load resolution is $50 \mathrm{nN}$. The Berkovich indenter is selected for this test. The maximum indenter displacement is $1.5 \mathrm{~mm}$. The maximum press-in depth is $500 \mu \mathrm{m}$, and the displacement resolution is $0.01 \mathrm{~nm}$.

2.2. Determination Method of Elastic Modulus and Hardness. Figure 2 shows the three-stage process curves of a typical sample under single loading, holding, and unloading [15]. In the loading stage, the indentation depth increases with the load, and elastoplastic deformation occurs. In the unloading stage, only elastic deformation can be recovered, so this stage can be used to determine the mechanical indexes such as elastic modulus and hardness of materials $[11,16]$.

Nanoindentation tests can obtain elastic modulus $E$, hardness $H$, contact stiffness $S$, creep stress index, fracture toughness, and so on. Elastic modulus and hardness are very important and commonly used. Contact stiffness is defined as the slope of the tangent line at the maximum load on the unloading curve, which can be expressed as follows:

$$
S=\left.\frac{d P}{d h}\right|_{h=h_{m}} .
$$

The reduced modulus is calculated as follows [17]:

$$
E_{r}=\frac{\sqrt{\pi}}{2 \beta} \cdot \frac{S}{\sqrt{A}} .
$$

The contact area $A$ is related to the contact depth $h_{c}$, which can be expressed as follows:

$$
A=f\left(h_{c}\right)
$$

For the Berkovich indenter, the contact depth can be calculated as follows:

$$
h_{c}=h-\varepsilon \frac{P}{S} .
$$

The hardness is expressed as follows:

$$
H=\frac{P}{A} .
$$

The yield strength can be obtained as follows:

$$
\sigma_{y} \approx \frac{H}{3}
$$

Elastic modulus can be calculated as follows:

$$
\frac{1}{E_{r}}=\frac{\left(1-v^{2}\right)}{E}+\frac{\left(1-v_{i}^{2}\right)}{E_{i}},
$$




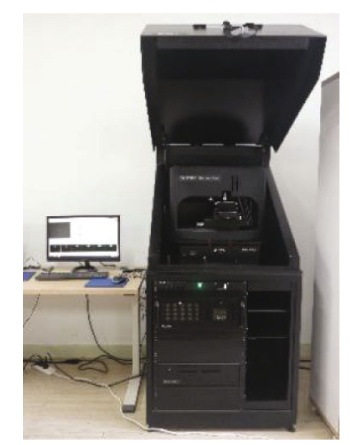

Figure 1: Agilent Nanoindenter G200.

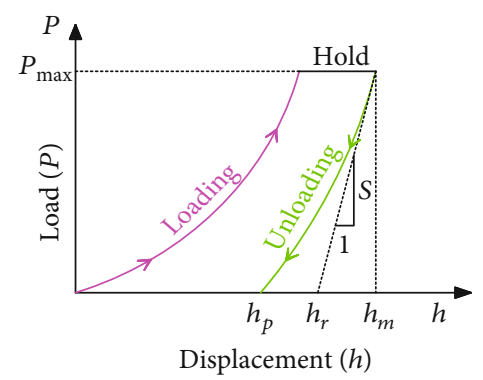

Figure 2: A typical load-displacement curve in nanoindentation tests $\left(h_{p}\right.$ : residual indentation depth after unloading; $h_{r}$ : indentation depth at the intersection of the tangent line at the maximum load on the unloading curve and the displacement axis; $h_{m}$ : maximum indentation depth before unloading).

or

$$
E=\left(1-v^{2}\right)\left[\frac{1}{E_{r}}-\frac{1-v_{i}^{2}}{E_{i}}\right]^{-1},
$$

where $\beta$ is an indenter correction coefficient and $\varepsilon$ is a constant related to the indenter shape. With regard to a regular pyramid Berkovich indenter, $\beta=1.034, \varepsilon=0.75$ [18]. $h_{c}$ (nm) is the contact depth. $A\left(\mathrm{~nm}^{2}\right)$ is the contact area, which can be calculated as $A=24.56 h_{c}^{2}$ [18]. $E_{r}$ is the reduced elastic modulus, which stands for the interaction effect between the indenter and indented material. $E_{i}$ and $v_{i}$ represent the elastic modulus and the Poisson ratio of the indenter, respectively. For the diamond indenter used in the present study, $E_{i}=1141 \mathrm{GPa}, v_{i}=0.07 . v$ is the Poisson ratio of the indented material. In this paper, the mechanical properties of the three minerals were measured by a noncrack pressing test.

2.3. Test Procedures. The nanoindentation tests require that the surface of the indented material should be smooth as possible. During the test, the diamond indenter is pressed vertically into the sample surface. The elastic deformation begins to occur on the sample surface. The plastic deformation and even crack occurs with the increase of load. The indentation is left after the completion of each point test. Finally, the load-displacement curve can be obtained, which is shown in Figure 2. The elastic modulus and hardness of the sample can be calculated by the characteristic parameters on the curve. Elastic modulus is an essential parameter for evaluating the brittleness of rock while hardness can be utilized to describe the difficulty of a rock surface being indented [1]. Both of which are important indexes to evaluate the mechanical properties of the materials $[16,18]$.

The granite in this paper is taken from the Qinling Mountains. The samples are relatively fresh and retain the structural characteristics of magma crystallization. It is a semi-idiomorphic granular granite and mainly composed of quartz, plagioclase, alkaline feldspar, and mica. The test procedures are detailed as follows:

(1) Firstly, the granite sample is processed into a cuboid with a length of $15 \mathrm{~mm}$, a width of $15 \mathrm{~mm}$, and a height of $5 \mathrm{~mm}$. The sample surface is polished with 100\#, 600\#, 800\#, 1000\#, 2000\#, 5000\#, and 7000\# gold matte paper in turn. The grinding time on each kind of gold matte paper is not less than 40 minutes. At the same time, a surface roughness meter is used to randomly scan the sample surface, thus ensuring that the $R a$ is not greater than $5 \mu \mathrm{m}$. Then, the sample is cleaned with ultrasonic waves to make sure that there is no debris on the sample surface. Finally, the prepared sample is placed in an oven at $50^{\circ} \mathrm{C}$ for 24 to 48 hours until it is completely dried up

(2) After the polishing and drying phases, the sample is put on the support platform within the work space of the indentation instrument at a temperature of 20 $\pm 1{ }^{\circ} \mathrm{C}$ and a relative humidity of $42 \%$. The sample surface is observed using an optical microscope to identify the minerals, and the indentation test on the mineral is carried out. Figure 3 shows microscopic images of quartz, feldspar, and mica. In this test, a single load-unload mode is used

(3) After the indentation tests, the sample is observed by SEM to obtain the morphology and distribution characteristics of various minerals and the residual indentation on different minerals. The semiquantitative phase analysis is carried out by XRD and a rock slice identification test to obtain the volume percentage of each mineral in granite

\section{Results and Discussion}

3.1. Mineral Microstructure and Content. Figure 3 shows microscopic images of quartz, feldspar, and mica. It can be seen that the surface of quartz is very smooth, feldspar is second, and the surface of biotite is black and biotite has a lamellar structure.

Figure 4 shows typical residual indentation images of quartz, feldspar, and mica. These images are obtained by SEM. The residual indentation of quartz is complete and clear, the residual indentation morphology is consistent with the indenter shape, and no obvious cracks occur in Figure 4(a), which indicates that the elastic properties of quartz is good. The residual indentation of feldspar is slightly deeper than that of quartz, and the indentation edge has a bulge deformation in Figure 4(b), which indicates that 


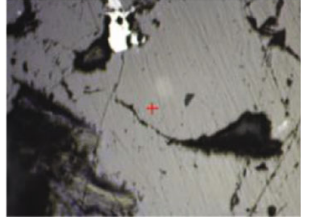

(a) Quartz

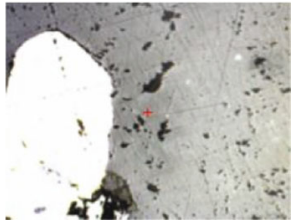

(b) Feldspar

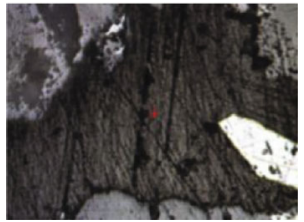

(c) Mica

Figure 3: Microscopic images of three minerals (magnification 250x).

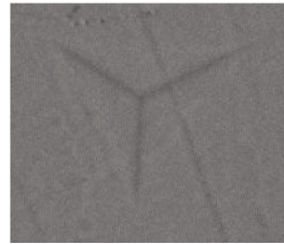

(a) Quartz

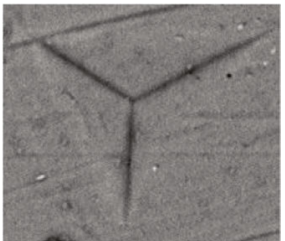

(b) Feldspar

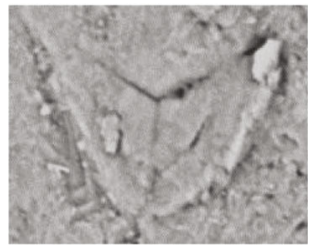

(c) Mica

Figure 4: Typical residual indentation images of three minerals.

the mechanical properties of feldspar is slightly worse than quartz. Slight flaking occurs around the residual indentation of mica, and the residual indentation morphology is incomplete and unclear in Figure 4(c), which indicates that the mechanical properties of mica is worst.

The composition and content of minerals can be obtained by X-ray diffraction (XRD) and rock slice identification test. Figure 5 shows the XRD energy spectrum of granite and the pie chart of the volume percentage of the main minerals. The results show that the granite contains $25.2 \%$ quartz, $61.6 \%$ feldspar $(26.5 \%$ potassium feldspar and $35.1 \%$ plagioclase), $10.9 \%$ mica, and $2.3 \%$ other minerals. Due to the small proportion of other minerals, their effects on the mechanical properties of granite are ignored.

3.2. Analysis of Elastic Modulus and Hardness of Minerals. According to the results of nanoindentation tests, the elastic modulus and hardness of the main minerals in granite can be obtained. In the calculation process, the Poisson ratio of quartz, feldspar, and mica are $0.20,0.25$, and 0.30 , respectively [19]. Material cracking under loading will affect the accuracy of elastic modulus and hardness, so the elastic modulus and hardness of the material are calculated by nanoindentation tests without cracking. The critical load for cracking of quartz and feldspar is between $20 \mathrm{mN}$ and $50 \mathrm{mN}$ and that of mica is between $5 \mathrm{mN}$ and $10 \mathrm{mN}$. Therefore, the maximum load of quartz and feldspar is $20 \mathrm{mN}$, and the loading time is 20 seconds. The maximum load of mica is $5 \mathrm{mN}$, and the loading time is 5 seconds. The loading rate is $1 \mathrm{mN} / \mathrm{s}$, and the holding time is 10 seconds for three minerals.

Figure 6 shows the load-displacement curves of nanoindentation for quartz, feldspar, and mica under loading and unloading. It can be seen that the loading and unloading process of minerals in granite can be divided into the compaction stage $(\mathrm{OA})$, the elastoplasticity stage $(\mathrm{AB})$, the holding stage $(\mathrm{BC})$, and the unloading stage (CD). The deformation of mica is the largest, feldspar is the second, and quartz is the smallest. The above law is consistent with the law of residual indentation deformation. The compaction stage of quartz is much shorter than mica. Under the same holding time, the creep deformation of mica is the largest, followed by feldspar and quartz. These indicate that quartz has a dense structure, high stiffness, and good mechanical properties, while mica has a relatively loose structure, small stiffness, and poor mechanical properties. 


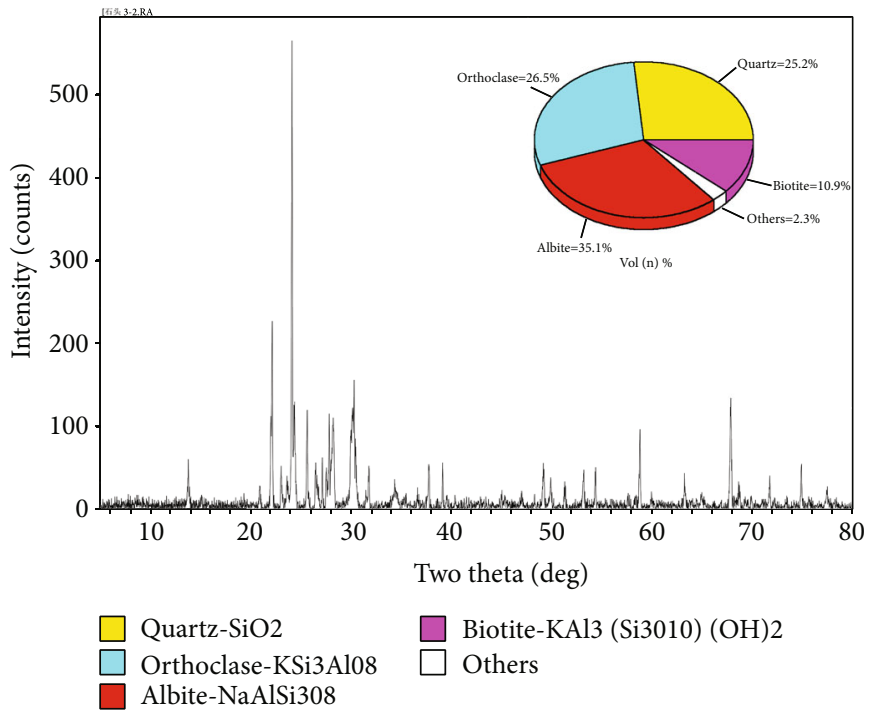

FIGURE 5: XRD energy spectrum of granite and pie chart of the volume percentage of the main minerals.

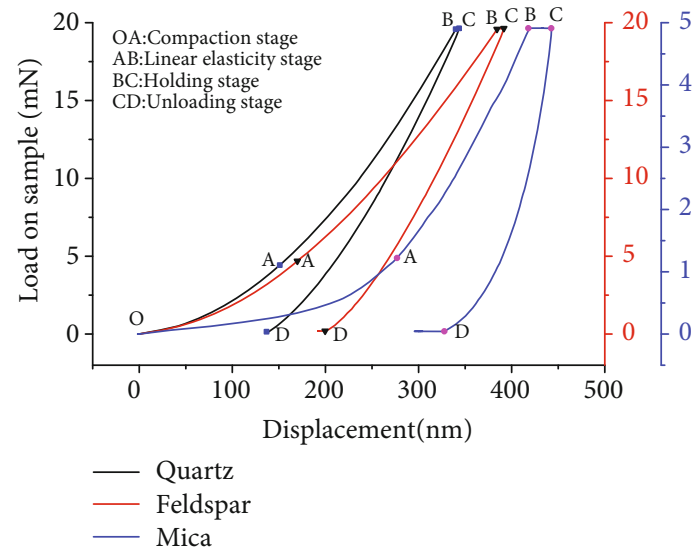

FIGURE 6: Load-displacement curves of quartz, feldspar, and mica.

Figure 7 is the distribution histogram of the elastic modulus and hardness of quartz. It can be seen that the distribution of the elastic modulus and hardness of quartz is in accord with the normal distribution and is concentrated. By statistical analysis and calculation, the elastic modulus of quartz is $101.34 \pm 9.53 \mathrm{GPa}$ and the hardness is $12.72 \pm$ $2.17 \mathrm{GPa}$.

Figure 8 is the distribution histogram of the elastic modulus and hardness of feldspar. It can be seen that the distribution of the elastic modulus and hardness of feldspar conforms to the normal distribution and is relatively concentrated. By statistical analysis and calculation, the elastic modulus of feldspar is $82.47 \pm 10.29 \mathrm{GPa}$ and the hardness is $9.20 \pm 1.68 \mathrm{GPa}$.

Figure 9 is the distribution histogram of the elastic modulus and hardness of mica. It can be seen that the amplitude of the elastic modulus and hardness of mica changes greatly. By statistical analysis and calculation, the elastic modulus of mica is $25.88 \pm 8.33 \mathrm{GPa}$ and the hardness is $1.78 \pm 0.75 \mathrm{GPa}$.

\section{Homogenization Methods and Techniques}

Granite is a three-phase composite material, which is composed of quartz, feldspar, and mica. These three minerals are randomly distributed. The elastic properties of these different minerals are obtained by nanoindentation tests. The relative content of each mineral is obtained by XRD and the rock slice identification test. On this basis, the macroscopic elastic properties of granite are estimated by the Self-consistent method, the Dilute method, and the MoriTanaka method.

4.1. Self-Consistent Method. The Self-consistent method was first used by Hershey for the study of polycrystals [20]. The method is further developed and used by Hill to study the elastic modulus of composites [21]. The Self-consistent method replaces the anisotropic composite with an idealized homogeneous continuum. This substitution is based on the equalization of strain energy stored or dissipated by the material at a certain volume range. When the scale range is much larger than the local characteristic size of the anisotropic material, the mechanical behavior of the two media is the same. The effective modulus of the composite material can be expressed as follows [22]:

$$
\bar{C}=C_{0}+\sum_{r=1}^{N=1} c_{r}\left(C_{r}-C_{0}\right)\left[I+\bar{P}_{r}\left(C_{r}-\bar{C}\right)\right]^{-1}
$$

where $C_{0}$ and $C_{r}$ are the modulus of the mineral with the largest content and the modulus of phase $r$, respectively. $c_{r}$ is the volume fraction of phase $r$. $I$ is the tensor related to the shape of the inclusion. $\bar{P}_{r}$ is the $P$ tensor when phase $r$ is placed in the unknown composite material as the matrix. It is related to the shape of the inclusion and the unknown modulus $\bar{C}$ of the composite. This is an implicit equation of the effective modulus of the composite. The self- 

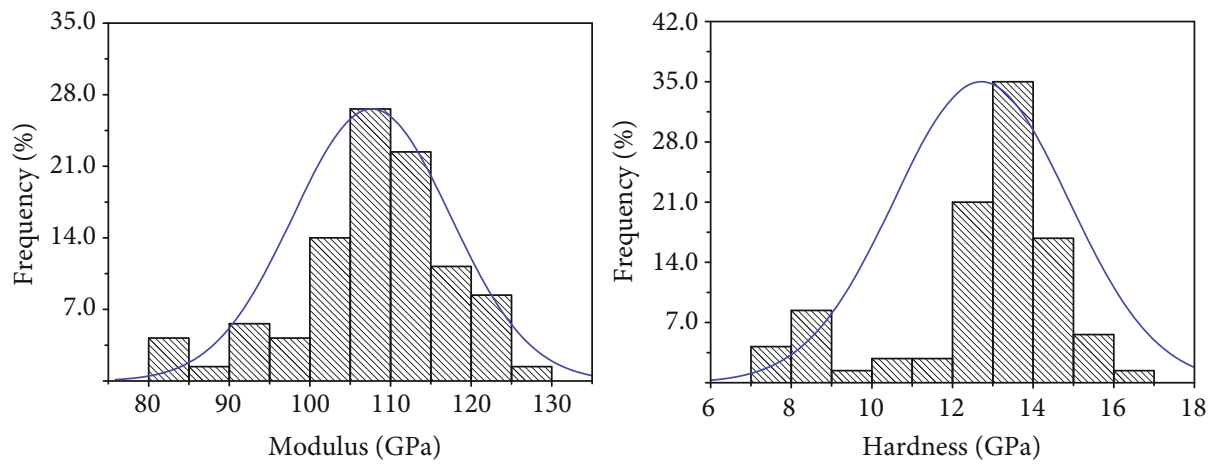

FIGURE 7: Distribution histogram of the elastic modulus and hardness of quartz.
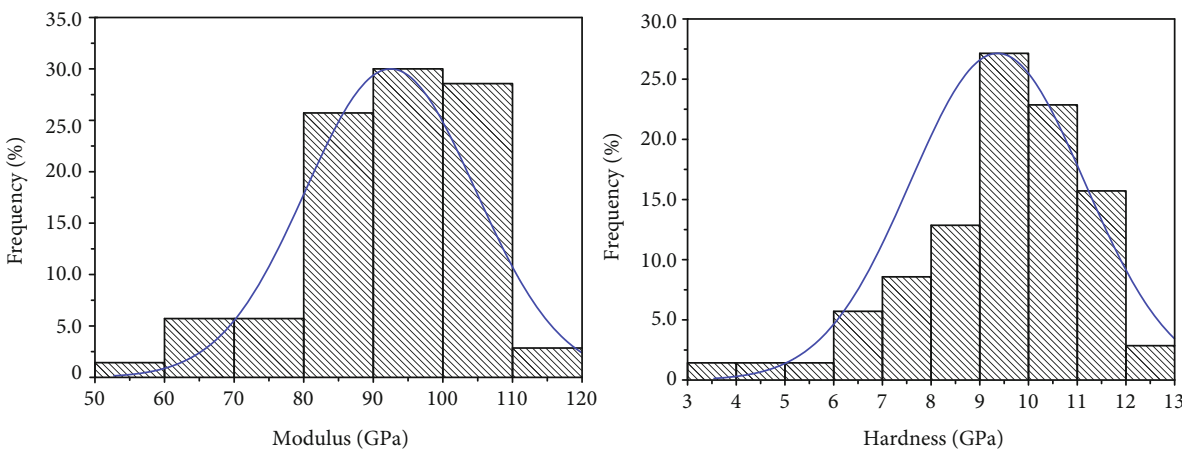

FIGURE 8: Distribution histogram of the elastic modulus and hardness of feldspar.

consistent method can be used to estimate the effective modulus of the composite by solving this equation.

The implicit equations of effective shear modulus and bulk modulus of granite are obtained by using the simplified algorithm for an isotropic tensor and are shown as follows:

$$
\begin{gathered}
G^{\mathrm{hom}}=\sum_{r=0} c_{r} \frac{5 G_{r} \cdot G^{\mathrm{hom}}\left(3 K^{\mathrm{hom}}+4 G^{\mathrm{hom}}\right)}{G^{\mathrm{hom}}\left(9 K^{\mathrm{hom}}+8 G^{\mathrm{hom}}\right)+6 G_{r}\left(K^{\mathrm{hom}}+2 G^{\mathrm{hom}}\right)}, \\
K^{\mathrm{hom}}=\sum_{r=0} c_{r} \frac{k_{r}\left(3 K^{\mathrm{hom}}+4 G^{\mathrm{hom}}\right)}{3 K_{r}+4 G^{\mathrm{hom}}},
\end{gathered}
$$

where $G^{\text {hom }}$ and $K^{\text {hom }}$ represent the effective shear modulus and bulk modulus of granite after homogenization, respectively. $G_{r}$ and $K_{r}$ are the shear modulus and bulk modulus of phase $r$, respectively. The calculation formulas are as follows:

$$
\begin{gathered}
G_{r}=\frac{E}{2(1+v)}, \\
K_{r}=\frac{E}{3(1-2 v)},
\end{gathered}
$$

where $E$ and $v$ are the elastic modulus and the Poisson ratio of the minerals, respectively.
4.2. Dilute Method. It is assumed that the concentration of inclusions in the composite are small, and the interactions between them are negligible. The multiple inclusion problem can be turned into a single inclusion problem, and the inclusions can be separated from each other [23]. The effective modulus of the composite is predicted as follows [22]:

$$
\bar{C}=C_{0}+\sum_{r=1}^{N-1} c_{r}\left[\left(C_{r}-C_{0}\right)^{-1}+P_{r}\right]^{-1} .
$$

Considering that there is no interaction between inclusions and assuming that inclusions are spherical particles, the macroscopic elastic properties of granite are obtained by the Dilute method and are shown as follows [14]:

$$
\begin{array}{r}
K^{\text {hom }}=K_{0}+\sum_{r=1}^{N} c_{r} \frac{\left(K_{r}-K_{0}\right)\left(3 K_{0}+4 G_{0}\right)}{3 K_{r}+4 G_{0}}, \\
G^{\text {hom }}=\sum_{r=1}^{N} c_{r} \frac{5 G_{0}\left(G_{r}-G_{0}\right)\left(3 K_{0}+4 G_{0}\right)}{G_{0}\left(9 K_{0}+8 G_{0}\right)+6 G_{r}\left(K_{0}+2 G_{0}\right)},
\end{array}
$$

where $K_{0}$ and $G_{0}$ are the bulk modulus and shear modulus of the minerals with the largest content. Other symbols have the same meanings as above.

4.3. Mori-Tanaka Method. The Mori-Tanaka method was proposed by Mori and Tanaka in 1973 when they were studying the work hardening of dispersion-hardened 

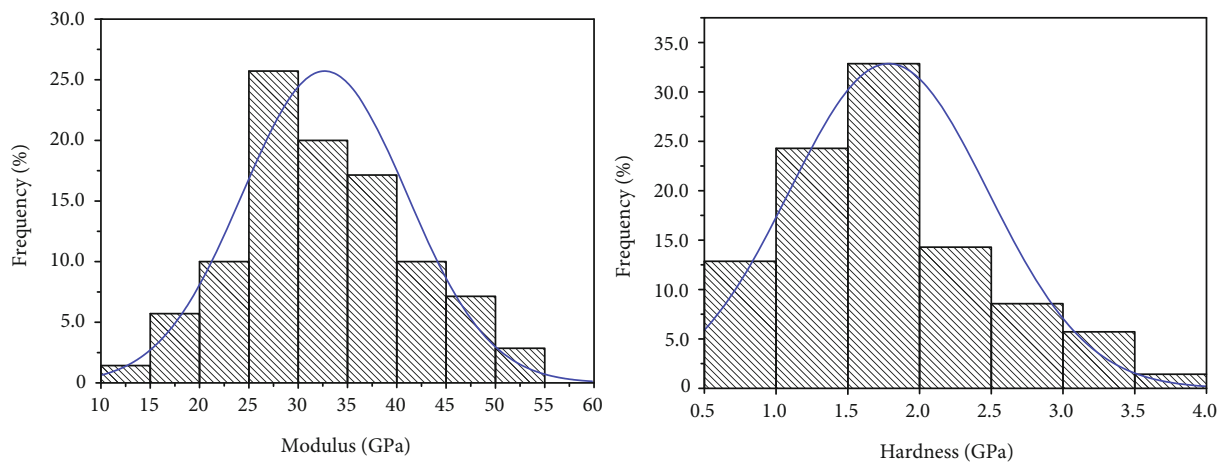

Figure 9: Distribution histogram of the elastic modulus and hardness of mica.

materials $[24,25]$. This is a method for calculating the equivalent elastic modulus of heterogeneous materials based on Eshelby's equivalent inclusion principle. The Mori-Tanaka method takes interactions between inclusions into account and assumes that each inclusion is embedded in an infinite matrix. The effective modulus of a composite can be expressed as follows [22]:

$$
\bar{C}=C_{0}+\sum_{r=1}^{N-1} c_{r}\left[\left(C_{r}-C_{0}\right)^{-1}+c_{0} P_{r}\right]^{-1}
$$

The bulk modulus and shear modulus of granite are expressed as follows:

$$
\begin{gathered}
K^{\mathrm{hom}}=\frac{\sum_{r=0} c_{r}\left(K_{r} / 3 K_{r}+4 G_{0}\right)}{\sum_{s=0} c_{s} / 3 K_{r}+4 G_{0}}, \\
G^{\mathrm{hom}}=\frac{\sum_{r=0} c_{r} G_{r} / G_{0}\left(9 K_{0}+8 G_{0}\right)+6 G_{r}\left(K_{0}+2 G_{0}\right)}{\sum_{s=0} c_{s} / G_{0}\left(9 K_{0}+8 G_{0}\right)+6 G_{s}\left(K_{0}+2 G_{0}\right)},
\end{gathered}
$$

where $K_{0}$ and $G_{0}$ are the bulk modulus and shear modulus of mica, respectively. Considering that the pore structure of mica is obvious, the bulk modulus and shear modulus of mica are expressed as follows:

$$
\begin{gathered}
K_{0}=\frac{4(1-\varphi) K_{s} G_{s}}{4 G_{s}+3 \varphi K_{s}}, \\
G_{0}=\frac{(1-\varphi) G_{s}}{1+6 \varphi\left(K_{s}+2 G_{s} / 9 K_{s}+8 G_{s}\right)},
\end{gathered}
$$

where $K_{s}$ and $G_{s}$ are the bulk modulus and shear modulus of mica regardless of pore structure, respectively. $\varphi$ is the porosity of mica, which is estimated to be $5 \%$ in this paper.

4.4. Comparative Analysis of Calculation Results. The equivalent bulk modulus and shear modulus of granite are obtained by the above methods and procedures. The elastic modulus and the Poisson ratio can be calculated as follows:

$$
E^{\text {hom }}=\frac{9 K^{\text {hom }} \cdot G^{\text {hom }}}{3 K^{\text {hom }}+G^{\text {hom }}},
$$

$$
v^{\text {hom }}=\frac{3 K^{\text {hom }}-2 G^{\text {hom }}}{6 K^{\text {hom }}+2 G^{\text {hom }}} .
$$

The mechanical parameters of granite obtained by three homogenization methods are shown in Table 1. It can be seen that the elastic modulus and the Poisson ratio calculated by three homogenization methods are in accordance with them obtained by uniaxial compression tests. The elastic modulus of granite obtained by the Self-consistent method, the Dilute method, and the Mori-Tanaka method are $74.13 \mathrm{GPa}, 76.59 \mathrm{GPa}$, and $73.91 \mathrm{GPa}$, respectively. The Poisson ratio of granite obtained by the three methods are $0.241,0.244$, and 0.246 , respectively. Compared with the measured values, the deviation rates of the elastic modulus are $26.5 \%, 30.7 \%$, and $26.1 \%$ and those of the Poisson ratio are $3.6 \%, 2.4 \%$, and $1.6 \%$, respectively.

Through comparative analysis of the advantages and disadvantages of three homogenization methods, the Selfconsistent method is more suitable for isotropic and homogeneous materials without a matrix and does not consider the material porosity, the Dilute method is suitable for materials with a small inclusion content and does not consider the interaction between inclusions, but the Mori-Tanaka method can consider the pores and the interaction between inclusions. The Mori-Tanaka method is suitable for the transition of granite mechanical parameters from microscale to macroscale.

Through comparative analysis of the calculation results with the measured values, the elastic modulus obtained by the three homogenization methods are higher than the measured value. The possible reasons are as follows: (1) Samples of a macromechanical property test are large in size and contain many defects such as microcracks and micropores. When the samples are under loading, the microcracks are more likely to propagate. (2) It is assumed that mineral particles are arbitrary spherical particles for three homogenization methods, while the actual shapes of mineral particles are quite different. (3) The actual distribution, arrangement, and bonding action of minerals in granite are different from the calculation assumptions of various methods.

Although the granite mechanical parameters obtained by the three homogenization methods are different from the measured values in a certain range, the homogenization method plays an important role in the evaluation of the 
TABLE 1: Compared analysis of the calculation results with the measured values.

\begin{tabular}{lcccc}
\hline & Bulk modulus: $K^{\text {hom }}(\mathrm{GPa})$ & Shear modulus: $G^{\text {hom }}(\mathrm{GPa})$ & Elastic modulus: $E^{\text {hom }}(\mathrm{GPa})$ & Poisson's ratio: $v^{\text {hom }}$ \\
\hline Self-consistent method & 47.64 & 29.88 & 74.13 & 0.241 \\
Dilute method & 49.77 & 30.80 & 76.59 & 0.244 \\
Mori-Tanaka method & 48.53 & 29.65 & 73.91 & 0.246 \\
Test measurement & - & - & 58.6 & 0.250 \\
\hline
\end{tabular}

mechanical properties of rock-soil materials and has an engineering practical value. It will be the focus and hotspot of future research on the analysis of factors causing deviation and the application of optimization homogenization method in rock-soil materials.

\section{Conclusion}

The elastic modulus and hardness of quartz, feldspar, and mica in granite were statistically analyzed by a nanoindentation test. The residual indentation information of three minerals in granite were analyzed by SEM. The relative content of three minerals in granite were obtained by XRD and a rock slice identification test. The Self-consistent method, the Dilute method, and the Mori-Tanaka method were used to realize the transition of granite mechanical parameters from microscale to macroscale. The main conclusions are as follows:

(1) The distribution of the elastic modulus and the hardness of the three minerals in granite is basically in accord with the normal distribution. The mechanical parameters of mica are more discrete, because the mechanical properties of mica are poor and the nanoindentation test is easily affected by other impurities

(2) The morphology and residual indentation of the three minerals in granite were obtained by SEM, which provides an effective method and reference for the study of rock mechanical properties. XRD and rock slice identification test shows that the content of quartz, feldspar, and mica in granite are $25.2 \%, 61.6 \%$, and $10.9 \%$, respectively

(3) Three homogenization methods were used to realize the transition of granite mechanical parameters from microscale to macroscale. The calculation results are in accordance with uniaxial compression test results. Among the three methods, the MoriTanaka method is more suitable for the transition of granite mechanical parameters from microscale to macroscale. The homogenization method of a composite plays an important role in studying the mechanical properties of rock-soil materials and has an engineering practical value. The research results provide a new method and an important reference for studying the macro-, micro-, and nanomechanical properties of rock

\section{Data Availability}

The data used to support the findings of this study are available from the corresponding author upon request.

\section{Conflicts of Interest}

The authors declare no conflict of interest.

\section{Acknowledgments}

The authors acknowledge the support from the National Natural Science Foundation of China (Nos. 51979225 and 52009107), the Natural Science Basic Research Plan in Shaanxi Province of China (No. 2020JQ-627), the Opening Research Fund of National Engineering Laboratory for Surface Transportation Weather Impacts Prevention (No. NEL2020-02), and the Ministry of Water Resources Public Welfare Industry Scientific Research Project (No. 201501034$04)$.

\section{References}

[1] Z. Ma, R. Pathegama Gamage, and C. Zhang, "Effects of temperature and grain size on the mechanical properties of polycrystalline quartz," Computational Materials Science, vol. 188, article 110138, 10 pages, 2021.

[2] Z. Ma, R. Pathegama Gamage, and C. Zhang, "Application of nanoindentation technology in rocks: a review," Geomechanics and Geophysics for Geo-Energy and Geo-Resources, vol. 6, no. 4, pp. 1-27, 2020.

[3] Y. Xue, J. Liu, P. G. Ranjith, X. Liang, and S. Wang, "Investigation of the influence of gas fracturing on fracturing characteristics of coal mass and gas extraction efficiency based on a multi-physical field model," Journal of Petroleum Science and Engineering, vol. 206, article 109018, 2021.

[4] Y. Xue, T. Teng, F. Dang, Z. Ma, S. Wang, and H. Xue, "Productivity analysis of fractured wells in reservoir of hydrogen and carbon based on dual-porosity medium model," International Journal of Hydrogen Energy, vol. 45, no. 39, pp. 20240-20249, 2020.

[5] C. Wang, Study of deformation behavior of nanocrystalline nickel using nanoindentation techniques, vol. 8, University of Tennessee, Knoxville, 2010.

[6] S. Naderi, M. A. Dabbagh, M. A. Hassan, B. A. Razak, H. Abdullah, and N. H. Abu Kasim, "Modeling of porosity in hydroxyapatite for finite element simulation of nanoindentation test," Ceramics International, vol. 42, no. 6, pp. 7543 7550, 2016

[7] M. Tanguy, A. Bourmaud, and C. Baley, "Plant cell walls to reinforce composite materials: relationship between 
nanoindentation and tensile modulus," Materials Letters, vol. 167, pp. 161-164, 2016.

[8] S. D. Viktorov, Y. I. Golovin, A. N. Kochanov et al., "Microand nano-indentation approach to strength and deformation characteristics of minerals," Journal of Mining Science, vol. 50, no. 4, pp. 652-659, 2014.

[9] W. Z. Zhu, J. J. Hughes, N. Bicanic, and C. J. Pearce, "Nanoindentation mapping of mechanical properties of cement paste and natural rocks," Materials Characterization, vol. 58, no. 11-12, pp. 1189-1198, 2007.

[10] F. Zhang, H. Guo, J. Zhao, and D. Hu, "Experimental study of micromechanical properties of granite," Chinese Journal of Rock Mechanics and Engineering, vol. 36, no. s2, pp. 38643872, 2017.

[11] K. Liu, M. Ostadhassan, and B. Bubach, "Applications of nanoindentation methods to estimate nanoscale mechanical properties of shale reservoir rocks," Journal of Natural Gas Science and Engineering, vol. 35, pp. 1310-1319, 2016.

[12] C. P. Bobko, B. Gathier, J. A. Ortega, F. J. Ulm, L. Borges, and Y. N. Abousleiman, "The nanogranular origin of friction and cohesion in shale-a strength homogenization approach to interpretation of nanoindentation results," International Journal for Numerical and Analytical Methods in Geomechanics, vol. 35, no. 17, pp. 1854-1876, 2011.

[13] Q. Chen, M. M. Nezhad, Q. Fisher, and H. Zhu, "Multi-scale approach for modeling the transversely isotropic elastic properties of shale considering multi-inclusions and interfacial transition zone," International Journal of Rock Mechanics and Mining Sciences, vol. 84, pp. 95-104, 2016.

[14] A. Abou-Chakra Guéry, F. Cormery, J. F. Shao, and D. Kondo, "A comparative micromechanical analysis of the effective properties of a geomaterial: effect of mineralogical compositions," Computers and Geotechnics, vol. 37, no. 5, pp. 585593, 2010.

[15] J. Hay, "Introduction to instrumented indentation testing," Experimental Techniques., vol. 33, no. 6, pp. 66-72, 2009.

[16] Y. T. Cheng, Z. Li, and C. M. Cheng, "Scaling relationships for indentation measurements," Philosophical Magazine A, vol. 82, no. 10, pp. 1821-1829, 2002.

[17] R. B. King, "Elastic analysis of some punch problems for a layered medium," International Journal of Solids and Structures, vol. 23, no. 12, pp. 1657-1664, 1987.

[18] W. C. Oliver and G. M. Pharr, "An improved technique for determining hardness and elastic modulus using load and displacement sensing indentation experiments," Journal of Materials Research, vol. 7, no. 6, pp. 1564-1583, 1992.

[19] M. F. Cai, Rock Mechanics and Engineering, Science Publishing House, Beijing, 2002.

[20] A. V. Hershey, "The elasticity of an isotropic aggregate of anisotropic cubic crystals," Journal of Applied Mechanics, vol. 21, pp. 236-241, 1964.

[21] R. Hill, "Continuum micro-mechanics of elastoplastic polycrystals," Journal of the Mechanics and Physics of Solids, vol. 13, no. 2, pp. 89-101, 1965.

[22] G. Shen, G. Hu, and B. Liu, Mechanics of Composite Materials, Tsinghua University Press, Beijing, (Second Edition) edition, 2013.

[23] A. Zaoui, "Continuum micromechanics: survey," Journal of Engineering Mechanics, vol. 128, no. 8, pp. 808-816, 2002.
[24] T. Mori and K. Tanaka, "Average stress in a matrix and average elastic energy of materials with misfitting inclusions," Acta Metallurgica et Materialia, vol. 42, no. 7, pp. 597-629, 1973.

[25] Y. Benveniste, "On the Mori-Tanaka's method in cracked bodies," Mechanics Research Communications, vol. 13, no. 4, pp. 193-201, 1986. 